\title{
Analisis Perkerasan Kaku Metode AASHTO 1993 dan Metode Austroads 2012 Terhadap Keekonomisan Biaya
}

\author{
M. Abi Hartono" ${ }^{1}$, Eva Azhra Latifa ${ }^{2)}$ \\ 1) Fakultas Teknik, Program Studi Teknik Sipil, Universitas Politeknik Negeri Jakarta, Kampus UI \\ Depok; Telp.021-7270036. Email: muhammad.abihartono@gmail.com \\ ${ }^{2)}$ Fakultas Teknik, Program Studi Teknik Sipil, Universitas Politeknik Negeri Jakarta, Kampus UI \\ Depok; Telp. 021-7270036. Email: evaashra@gmail.com
}

\begin{abstract}
Abstrak
Terdapat banyak metode dalam mendesain tebal perkerasan kaku, diantaranya metode AASHTO 1993 dan metode AUSTROADS 2012. Pemilihan metode perencanaan yang tepat untuk suatu pekerjaan mempunyai peranan penting terkait dengan indikator keberhasilan suatu proyek dalam hal ini konstruksi perkerasan kaku yang memenuhi syarat teknis dan biaya yang ekonomis. Oleh karena itu, dilakukan penelitian untuk membandingkan tebal pelat beton dan biaya yang diperlukan konstruksi perkerasan kaku dengan lapisan tanah dasar yang diberi perkuatan dengan penambahan semen dibandingkan dengan lapisan tanah dasar yang diberi lapisan geotekstil. Tujuan penelitian ini adalah : menetukan tebal perkerasan kaku dan memilih biaya yang lebih ekonomis. Tebal pelat beton menggunakan metode AASHTO 1993 dan Austroad 2012 dihitung serta dianalisis biaya yang paling ekonomis dari kombinasi tanah dasar, pondasi atas, serta struktur plat beton. Hasil penelitian menunjukkan bahwa apabila menggunakan metode AASHTO 1993 menghasilkan tebal lean concrete $10 \mathrm{~cm}$ dan ketebalan pelat beton $27 \mathrm{~cm}$. Sedangkan untuk metode AUSTROADS 2012 menghasilkan tebal lean concrete $10 \mathrm{~cm}$ dan ketebalan pelat beton $21 \mathrm{~cm}$. Biaya yang paling murah didapatkan dari kombinasi (Perkerasan AUSTROAD, Tanah Stabilisasi, dan Pondasi Bawah) memerlukan biaya sebesar Rp.71,394,879,243
\end{abstract}

Kata kunci : AASHTO, autroads, perkerasan kaku, tebal pelat, biaya.

\begin{abstract}
There are many methods in designing rigid pavement thickness, including the 1993 AASHTO method and the AUSTROADS 2012. The selection of the right planning method for a job has an important role related to the success indicators of a project in this case rigid pavement construction that meets technical requirements and economical costs. Therefore, a study was conducted to compare the thickness of concrete slabs and the costs required for rigid pavement construction with a subgrade layer reinforced with the addition of cement compared to a subgrade layer given a geotextile layer. The purpose of this study is to determine the thickness of the rigid pavement and choose a more economical cost. The thickness of concrete slabs using the AASHTO 1993 and Austroad 2012 methods is calculated and analyzed the most economical cost of the combination of subgrade, upper foundation, and concrete plate structure. The results showed that when using the 1993 AASHTO method it produced a lean concrete thickness of $10 \mathrm{~cm}$ and a thickness of a concrete plate of $27 \mathrm{~cm}$. Whereas the AUSTROADS 2012 method produces a lean concrete thickness of $10 \mathrm{~cm}$ and a thickness of a concrete plate of 21 $\mathrm{cm}$. The lowest cost obtained from the combination (Pavement AUSTROAD, Soil Stabilization, and Lower Foundation) requires a fee of $R p .71,394,879,243$
\end{abstract}

Keywords: AASHTO, austroads, rigid pavement, plate thickness, cost.

\section{PENDAHULUAN}

Kemajuan teknologi yang disertai pesatnya pertambahan jumlah kendaraan, menuntut para akademisi terutama di bidang teknik sipil untuk memperdalam kemampuannya dalam meningkatkan sarana insfrastruktur terutama jalan. Perlu perencanaan jalan yang matang agar tingkat pelayanan, kenyamanan, dan keamanan pengguna jalan bisa terwujud (Apriyatno, 2015).

Berkurangnya waktu dan biaya perjalanan serta peningkatan keselamatan merupakan hasil akhir dari sistem jalan yang dirancang dengan baik. Jalan tol Lingkar Luar Bogor atau disebut Bogor Outer Ring Road (BORR) dibangun sebagai salah satu solusi untuk mengatasi tingginya volume kendaraan yang berasal dari kota - kota penyangga di 
sekitar Bogor dan untuk meningkatkan pertumbuhan ekonomi wilayah Bogor dan sekitarnya. Dengan dibangunnya BORR diharapkan para investor akan melirik kotakota penyangga di sekitar Bogor sebagai alternative tujuan investasi.

Ruas jalan Sentul SelatanKedunghalang merupakan jalan tol yang memiliki lalu-lintas yang padat. Kendaraan yang melintasi jalan tol Sentul SelatanKedunghalang di dominasi dari golongan 1 sampai dengan golongan 5 yang memiliki bermacam-macam junlah sumbu kendaraan niaga, sehingga tentu saja kapasitas dan pelayanan perkerasan jalannya harus memenuhi syarat teknis menurut fungsi maupun volume lalu lintas.

Perkerasan kaku yaitu perkerasan yang menggunakan semen sebagai bahan ikat sehingga mempunyai tingkat kekakuan yang relatif cukup tinggi bila dibandingkan dengan perkerasan lentur. Pemilihan ruas yang dilakukan pada lokasi yang dipilih ini bertujuan untuk mendapatkan data jumlah dan jenis kendaraan sehingga dapat digunakan untuk membandingkan metode perhitungan mana yang paling efisien (Ardiyatmo, 2007).

Tujuan penelitian ini adalah Menentukan tebal perkerasan kaku menggunakan metode AASHTO 1993 dan metode AUSTROADS 2012. Menentukan konstruksi yang lebih ekonomis jika daya dukung tanah ditingkatkan dengan stabilisasi semen Portland atau dengan lapisan geotekstil.

\section{METODE}

\section{Metode penelitian}

Pelaksanaan konstruksi jalan diatas tanah lunak dengan perkuatan geotekstil dapat menghindarkan terjadinya keruntuhan lokal pada tanah lunak karena rendahnya daya dukung tanah. Keuntungan penggunaan geotekstil pada pelaksanaan jalan diatas tanah lunak adalah kecepatan dalam pelaksanaan dan biaya yang relatif lebih murah dibandingkan dengan metode penimbunan konvensional (Bethary et. al. 2015).

Pemasangan geotekstil di lapisan tanah dasar akan menyebabkan daya dukung meningkat. Dari perhitungan analasis Plaxis V.8.2 daya dukung tanag yang diberi perkuatan geotekstil pada lapisan tanah dasar adalah sebesar $590.04 \mathrm{KN} / \mathrm{m} 2$, faktor angka aman didapatkan hasil 1,53>1,2 (aman) (Cahyono \& Rifa'I, 2018).

Sedangkan daya dukung tanah tanpa perkuatan geotekstil pada lapisan tanah dasar sebesar 486,27 KN/m2, faktor angka aman didapatkan hasil 1,51 > 1,2 (aman). Dari hasil perhitungan manual, didapatkan daya dukung ultimit tanah sebesar tanpa perkuatan geotekstil sebesar 558,58 KN/m2. Daya dukung ijin tanah sebesar 186,20 KN/m3, faktor angka aman akibat beban statis sebesar 2,21 > 1,2 (aman), faktor angka aman akibat beban dinamis sebesar 1,87>1,2 (aman), faktor aman akibat beban kombinasi sebesar $1,59>1,2$ (aman) (Hardiyatmo, 2011). Sehingga dapat disimpulkan lapisan tanah dasar tersebut tergolong jenis lapisan tanah dasar yang aman untuk Pembangunan Jalan Pocosari - Greges Yogyakarta (Hendarsin, 2000)

Ruas jalan tol Bogor Ring Road seksi 1 ruas Sentul Selatan - Kedung Halang (STA 0+000 - STA 3+850) dengan panjang 3,85 km. Ruas jalan tol ini memiliki 3 lajur dengan lebar masing - masing 3,6 m dengan lebar bahu luar $3 \mathrm{~m}$, bahu dalam $1,5 \mathrm{~m}$, dan lebar median 5,5 $\mathrm{m}$. Selengkapnya, dapat dilihat pada Gambar 1.

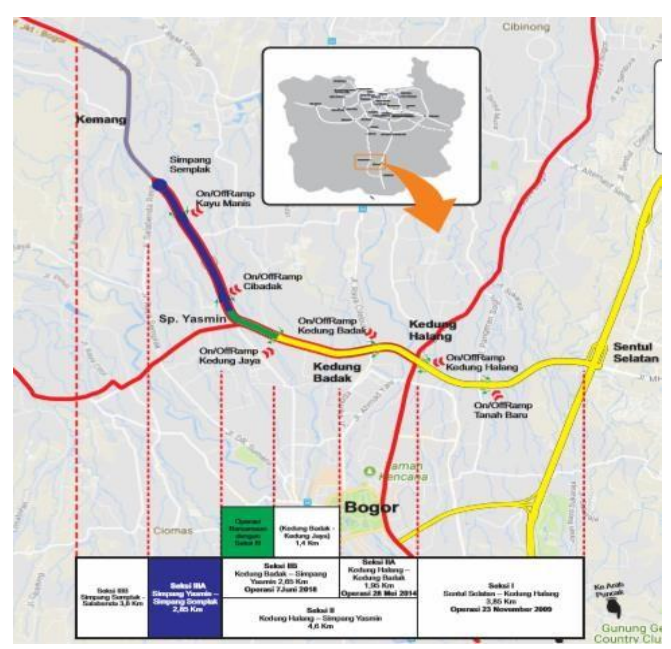

Gambar 1. Trase Rencana Jalan Tol Bogor Ring Road

(Sumber: PT. Marga Sarana Jabar, 2019)

Selanjutnya yaitu tahapan pengumpulan data pada tahap ini dilakukan perumusan objek serta permasalahan yang akan dibahas, yaitu Analisis tebal perkerasan kaku Metode AASHTO 1993, tebal perkerasan kaku metode AUSTROADS 2012, serta biaya untuk lapisan tanah dasar yang diberi perkuatan dengan penambahan semen 
dibandingkan dengan diberi lapisan geotekstil. Kemudian dilakukan studi literatur dan pencarian referensi tugas akhir serta jurnal mengenai perkerasan kaku, konfigurasi sumbu kendaraan, umur rencana, tinjau dengan langkah kerja dan biaya secara global. Kemudian menentukan lokasi penelitian.

Selanjutnyan pengambilan data sekunder dilakukan dengan membuat surat permintaan ke PT. Marga Sarana Jabar, data yang dibutuhkan yaitu data lalu lintas harian rata - rata, data geometrik, data teknis, gambar proyek, data CBR tanah, daftar faktor kehilangan bahan, dan daftar harga satuan. Dengan awalan seperti pada Tabel 1. berikut yaitu data LHR

Tabel 1. Data LHR Ruas Jalan Tol BORR Tahun 2015-2020

\begin{tabular}{lllllll}
\hline Tahun & Gol I & Gol II & Gol III & Gol IV & Gol V & Total \\
\hline 2015 & 39098 & 1999 & 565 & 77 & 58 & 41797 \\
2016 & 41996 & 2029 & 636 & 83 & 57 & 44801 \\
2017 & 40109 & 1950 & 790 & 94 & 61 & 43004 \\
2018 & 41914 & 1838 & 796 & 93 & 60 & 44701 \\
2019 & 43547 & 1811 & 780 & 95 & 54 & 46287 \\
2020 & 43978 & 1755 & 890 & 102 & 56 & 46781 \\
\hline
\end{tabular}

Sumber : PT. Marga Sarana Jabar

Dimana data LHR ruas Jalan Tol Borr terdiri dari tahun 2015- 2020, dengan tiap golongan kendaraan menurut golongan jasamarga.

\section{HASIL DAN PEMBAHASAN}

Analisis Perkerasan kaku menggunakan Metode AASHTO 1993 dan metode AUSTROADS 2012, kesesuaian antara tebal perkerasan kaku hasil perencanaan dan biaya yang lebih ekonomis diantara pekerjaan lapisan tanah dasar yang diberi perkuatan dengan penambahan semen dan lapisan tanah dasar diberi lapisan geotekstil. Seperti analisis nilai vehicle damage factor (VDF) pada Tabel 2 berikut:

Parameter Parameter analisis perkerasan kaku menggunakan metode AASHTO 1993 meliputi:

\section{Analisis Lalu Lintas (Traffic Design)}

Dalam melakukan analisis lalu lintas dapat menggunakan data primer ataupun data sekunder. Data primer didapat berdasarkan survey di lapangan. Pada akhirnya, untuk keamanan menggunakan data sekunder yang bersumber dari PT. Marga Sarana Jabar
Berikut data ESAL tahun 2020 - 2039 yang terdapat pada Tabel 3:

Tabel 2. Nilai Vehicle damage factor AASHTO (VDF)

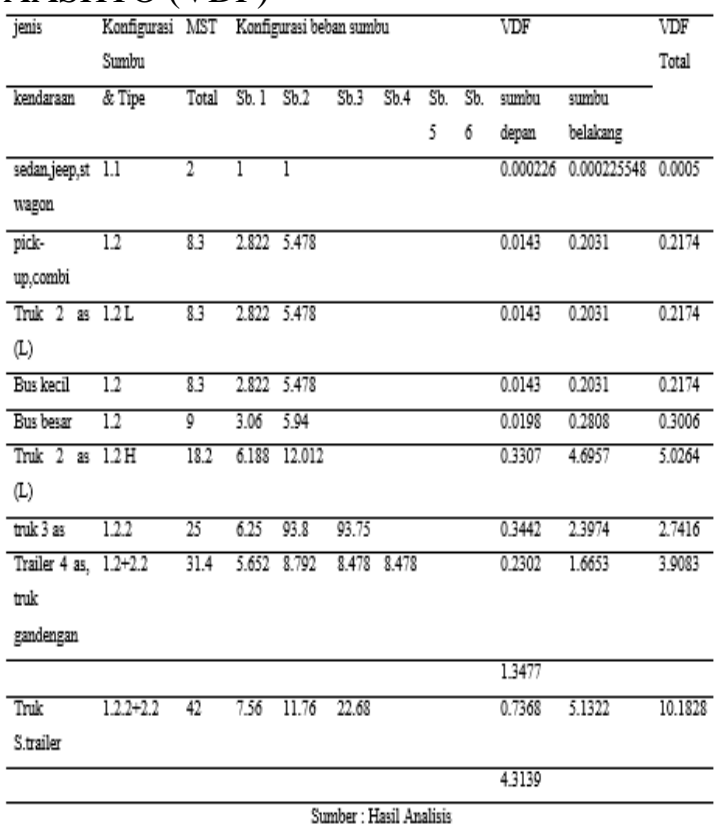

Tabel 3. Data Esal Tahun 2020-2039

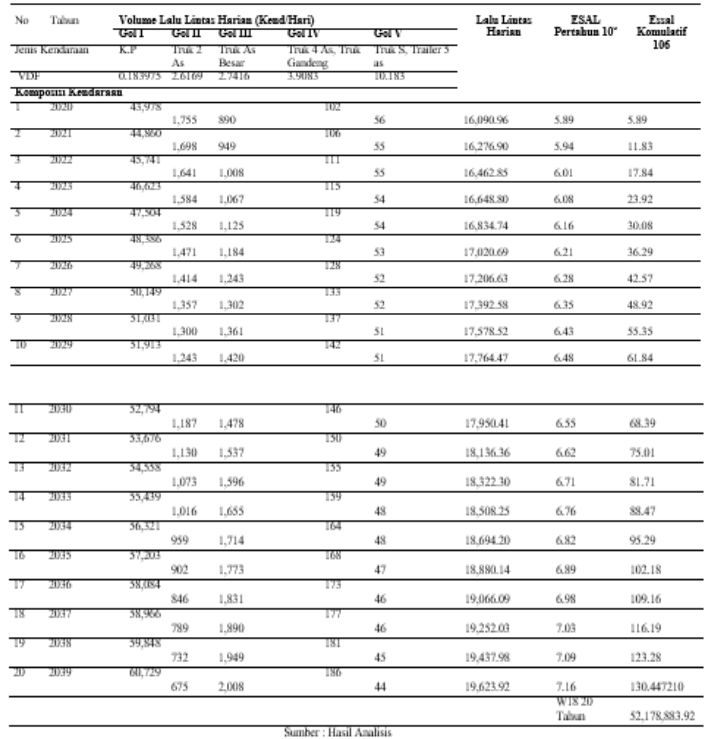

\section{Modulus Reaksi Tanah Dasar Efektif (k)}

Dalam perencanaan perkerasan kaku ini digunakan CBR sebesar 6\%, maka nilai CBR akan dikonversikan ke nilai Modulus Resilien (MR) dengan menggunakan persamaan sebagai berikut dan di plotkan pada grafik Gambar 2: 


$$
\begin{aligned}
& \mathrm{MR}=1.500 \times \mathrm{CBR} \\
& \mathrm{MR}=1.500 \times 6 \\
& \mathrm{MR}=\mathbf{9 0 0 0} \mathbf{p s i}
\end{aligned}
$$

Sehingga didapat nilai $\mathrm{k}$ dengan persamaan :

$$
\begin{array}{ll}
\mathrm{K} & =\mathrm{MR} / \mathbf{1 9 , 4} \\
\mathrm{K} & =9.000 / 19,4 \\
\mathrm{~K} & =463,918 \text { psi dibulatkan } \mathbf{4 6 4} \text { psi. }
\end{array}
$$

Rigid pavement menggunakan lean concrete dibawah pelat beton $10 \mathrm{~cm}$.

Loss of Support $: \mathbf{L S}=\mathbf{1}$

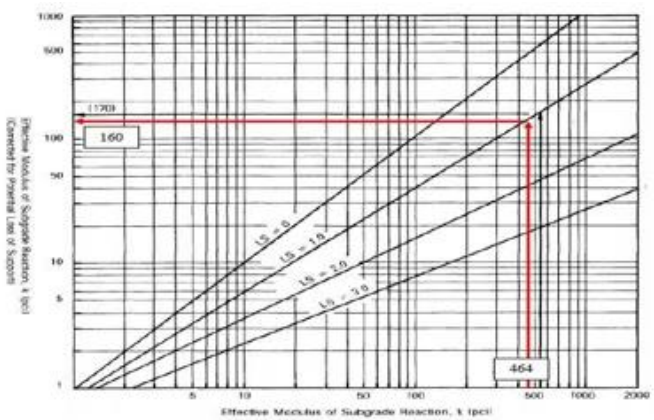

Ganbar 2. Effective Modulus of Subgrade Reaction, k (pci).

Dengan mendesain harus mengacu dengan tabel plat beton AASHTO 1993 sebagai berikut pada Tabel 4 .

Tabel 4. Parameter Desain Tebal Plat Beton AASHTO

\begin{tabular}{rcc}
\hline No. & Parameter & Desain \\
\hline 1 & Umur Rencana & 20 tahun \\
\hline 2 & ESAL komullatif & $52.178 .883,92$ \\
\hline 3 & Terminal Serviceability $\left(\mathrm{p}_{\mathrm{t}}\right)$ & 2,5 \\
\hline 4 & Initial Serviceability $\left(\mathrm{p}_{\mathrm{o}}\right)$ & 4,5 \\
\hline 5 & Total loss of serviceability $(\Delta \mathrm{PSI})$ & 2 \\
\hline 6 & Reliability $(\mathrm{R})$ & $95 \%$ \\
\hline 7 & Standard normal deviation $\left(\mathrm{Z}_{\mathrm{R}}\right)$ & $-1,645$ \\
\hline 8 & Standard deviation $\left(\mathrm{S}_{\mathrm{O}}\right)$ & 0,3 \\
\hline 9 & Modulus reaksi tanah dasar efektif $(\mathrm{k})$ & 160 \\
\hline 10 & Modulus elastisitas beton $\left(\mathrm{E}_{\mathrm{c}}\right)$ & $4.021 .227,80$ \\
\hline 11 & Kuat lentur beton $\left(\mathrm{S}_{\mathrm{c}}\right)$ & 640 \\
\hline 12 & Koefisien drainase & 1,25 \\
\hline 13 & Koefisien transfer beban & 2.5 \\
\hline & Sumber : $\mathrm{Hasil}$ Analisis
\end{tabular}

Dengan persamaan tabel plat beton yaitu didapat nilai tebal perkerasan kaku rencana (D) adalah 10, 325 inci dengan hitungan sebagai berikut:

$$
\begin{gathered}
\log _{10} \cdot W_{18}=Z_{R} \cdot S_{O}+7,35 \log _{10}(D+1)-0,06+\frac{\log _{10}\left[\frac{\Delta P S I}{4,5-1,5}\right]}{1+\frac{1,624 X 10^{7}}{(D+1)^{8,46}}}+ \\
(4,22-0,32 P t) x \log _{10} \frac{s^{\prime} c . c d x\left[D^{0,75}-1,132\right]}{215,63 x J X\left[D^{0,75}-\frac{18,45}{(E C: k)^{0,25}}\right]} \\
\log _{10} \cdot 52.178 .883,92 \\
=-1,645.0,3+7,35 \log _{10}(D+1)-0,06+\frac{\log _{10}\left[\frac{2}{4,5-1,5}\right]}{1+\frac{1,624 X 10^{7}}{(D+1)^{8,46}}} \\
+(4,22-0,32.2,5) x \log _{10} \frac{640,1,25 x\left[D^{0,75}-1,132\right]}{215,63 \times 2,5 X\left[D^{0,75}-\frac{18,42}{(4.021 .227,80: 160)^{0.25}}\right]}
\end{gathered}
$$

Cek persamaan OK: 7,7175

\section{Dengan Menggunakan Metode Austroad 2012}

Data LHR pada metode ini yang digunakan yaitu pada Tabel 5:

Tabel 5. Data LHR 2020 Ruas Jalan Tol Sentul Selatan - Kedunghalang

\begin{tabular}{ccc}
\hline No & $\begin{array}{c}\text { Konfigurasi } \\
\text { Sumbu \& Tipe }\end{array}$ & $\begin{array}{c}\text { LHR 2020 } \\
\text { (Kend/hari) }\end{array}$ \\
\hline 1 & 1.2 & 1.221 \\
\hline 2 & 1.1 .2 & 844 \\
\hline 3 & 1.2 .2 & 46 \\
\hline 4 & 1.2 .2 .2 & 22 \\
\hline 5 & $1.2-2.2$ & 80 \\
\hline 6 & $1.2 .2-2.2$ & 20 \\
\hline 7 & $1.2 .2-2.2 .2$ & 26 \\
\hline
\end{tabular}

\section{Sumber : Hasil Analisis}

Didapat dengan perhitungan jumlah sumbu berdasarkan jenis dan bebannya dilihat pada Tabel 6.

Tabel 6. Perhitungan Jumlah sumbu berdasarkan Jenis dan Bebannya

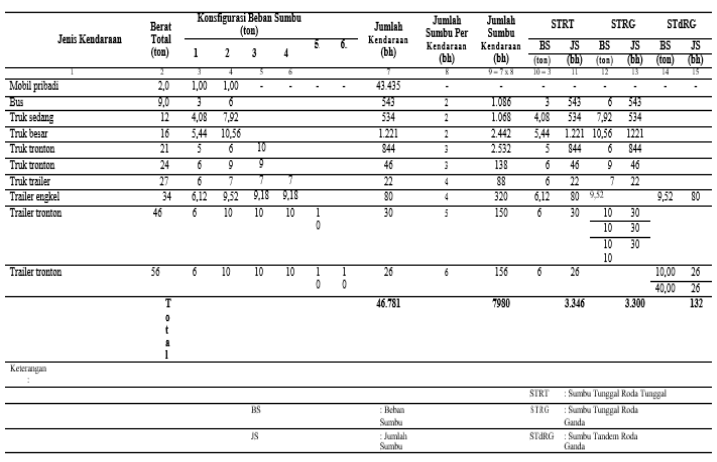


Perhitungan Komulatif Sumbu Kendaraan Selama Umur Rencana

$\mathrm{N}_{\mathrm{DT}}=365 \times$ AADT $\mathrm{x}$ DF $\mathrm{x} \% \mathrm{HV} / 100 \times \mathrm{LDF} \times$ CGF $x$ N NVAG

Umur Rencana $=20$ Tahun

$\mathrm{P}=20$

$\mathrm{R}=4,8 \%$

$$
C G F=\frac{(1+0,01 R)^{P}-1}{0,01 R}
$$

$$
C G F=\frac{(1+0,01 \times 4,8)^{20}-1}{0,01 \times 4,8}=32,37
$$

\section{2. $\mathrm{AADT}=\mathbf{7 9 8 0}$}

\section{NHVAG = luar Kota $=\mathbf{2 , 8}$ tabel 7.6} metode austroud 2017

4. DF $=\mathbf{0 , 5}(0,5-1)$

5. LDF

$=\mathbf{0 , 6 5}$ tabel LDF 3 Lajur

Dalam Kota

6. \% HV

$$
=12 \%
$$

$\mathrm{N}_{\mathrm{DT}}=365 \times$ AADT $\times$ DF $\mathrm{x} \% \mathrm{HV} / 100 \times \mathrm{LDF} \times$ CGF $x$ N $\mathrm{N}_{\mathrm{HAC}}$

$\mathrm{N}_{\mathrm{DT}}=365 \times 7980 \times 0,5 \times 12 / 100 \times 0,65 \times 32,3$ $\mathrm{x} 2,8$

\section{$\mathrm{N}_{\mathrm{DT}}=\underline{10 \times 10^{7} \text { HVAG }}$}

Dengan grafik didapatkan hasil pada Gambar 3. sebagai berikut.

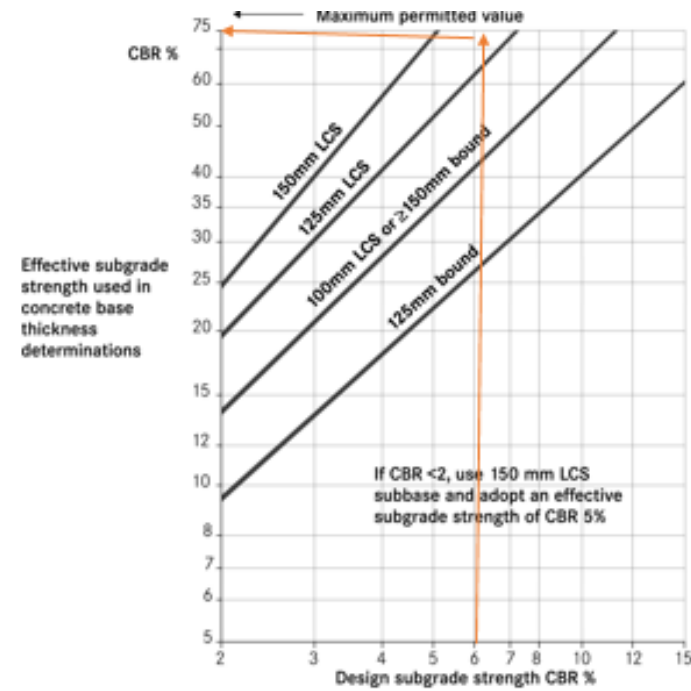

Gambar 3. Grafik Hasil Perhitungan Komulatif Sumbu Kendaraan Selama Umur Rencana

Dan faktor beban didapat yang tertera pada Tabel 7. sebagai berikut:
Tabel 7. Hasil dari faktor beban

\begin{tabular}{cccccc}
\hline \multirow{2}{*}{ Tipe Perkerasan } & \multicolumn{5}{c}{ Desain Keandalan Proyek } \\
\cline { 2 - 6 } & $80 \%$ & $85 \%$ & $90 \%$ & $95 \%$ & $97,5 \%$ \\
\hline PCP & 1,15 & 1,15 & 1,20 & 1,30 & 1,35 \\
Dowel dan CRCP & 1,05 & 1,05 & 1,10 & 1,20 & 1,25 \\
\hline
\end{tabular}

Sedangkan ketebalan dasar menunjukan sekitar 230 mm pada Gambar 3:

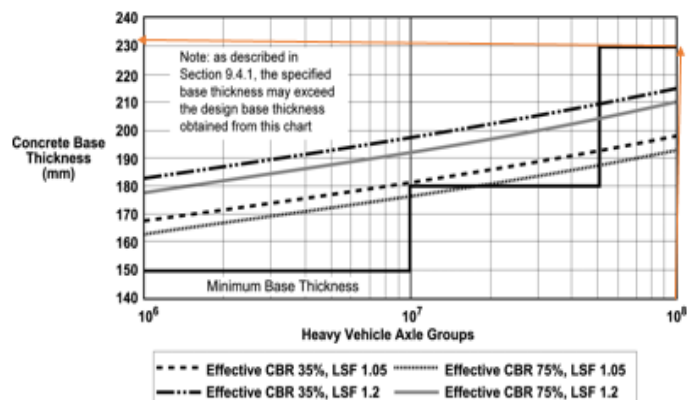

Gambar 3. Grafik ketebalan dasar

\section{Analisis Biaya Perkerasan Kaku}

Berdasarkan hasil analisis yang telah dilakukan, maka dapat dilakukan tabulasi analisis biaya pekerjaan Lean Concrete menggunakan metode AASHTO 1993 dilihat pada Tabel 8 Analisis Biaya Pekerjaan Lean Concrete Metode AASHTO 1993 Per $m^{2}$

Tabel 8. Analisis Biaya Pekerjaan Lean Concrete Metode AASHTO 1993 Per $\mathrm{m}^{2}$

\begin{tabular}{ccc}
\hline Komponen Pekejjan & Harga per $m^{3}$ & ${\text { Harga per } m^{2}}^{2}$ \\
\hline Tebal LC 10 cm & Rp. 1.207.647,35 & Rp. 120.764,7 \\
\hline \multicolumn{3}{c}{ Sumber. Hasil Analisis }
\end{tabular}

Lebar yang ditinjau

$=(($ jumlah lajur $\mathrm{x}$ lebar lajur $)+$ lebar bahu dalam + lebar bahu luar ) $\mathrm{x}$ jumlah jalur $=((3 \times 3.5)+1+2.5)$ $\mathrm{x} 2=28 \mathrm{~m}$

Panjang jalan $=3,85 \mathrm{~km}=3850 \mathrm{~km}$

Tebal Perkerasan $\quad=10 \mathrm{~cm}=0,1 \mathrm{~m}$ Volume total pekerjaan $=3850 \times 28 \times 0,1=$ $10.780 \mathrm{~m}^{3}$

Tabel 9. analisis biaya perkerasan kaku Metode AASHTO 1993 sepanjang 3,85

\begin{tabular}{cccc}
\hline Komponen Pekerjaan & Volume Total & Harga per $m^{3}$ & Harga total \\
\hline Tebal $L C 10 \mathrm{~cm}$ & 10.780 & Rp. $1.207 .647,35$ & Rp. 13.018 .438 .415 \\
& & \\
\hline & Sumber: Hasil Analisis &
\end{tabular}




\section{Analisis Biaya Perkerasan Kaku Metode Austroad 2012}

Berdasarkan hasil analisis yang telah dilakukan, maka dapat dilakukan tabulasi analisis biaya pekerjaan Lean Concrete menggunakan metode AUSTROADS 2012 dilihat pada tabel 5.48 dan Tabel 10 Analisis Biaya Pekerjaan Lean Concrete Metode AUSTROADS 2012

Tabel 10. Analisis Biaya Pekerjaan Lean Concrete Metode AUSTROADS 2012

\begin{tabular}{cll}
\hline Komponen Pekerjaan & Harga per $m^{3}$ & Harga per $m^{2}$ \\
\hline Tebal $L C 10 \mathrm{~cm}$ & Rp. $1.207 .647,35$ & Rp. $120.764,7$ \\
\hline \multicolumn{3}{c}{ Sumber: Hasil Analisis }
\end{tabular}

Lebar yang ditinjau

$=(($ jumlah lajur $\mathrm{x}$ lebar lajur $)+$ lebar bahu dalam + lebar bahu luar ) x jumlah jalur

$=((3 \times 3.5)+1+2.5) \times 2=28 \mathrm{~m}$

Panjang jalan $=3,85 \mathrm{~km}=3850 \mathrm{~km}$

Tebal Perkerasan $\quad=10 \mathrm{~cm}=0,1 \mathrm{~m}$

Volume total pekerjaan $=3850 \times 28 \times 0,1$

$$
=10.780 \mathrm{~m}^{3}
$$

Tabel 9. Analisis Biaya Perkerasan kaku Metode AUSTROADS 2012 sepanjang

\begin{tabular}{cccc}
\hline Komponen Pekerjaan & Volume Total & Harga per $m^{3}$ & Harga total \\
\hline Tebal $L C 10 \mathrm{~cm}$ & 10.780 & Rp. 1.207.647,35 & Rp. 13.018 .438 .415 \\
& & & \\
\hline & Sumber: Hasil Analisis
\end{tabular}

Dengan simulasi biaya sebagai berikut: Berdasarkan hasil perhitungan biaya di dapatkan pada Pekerjaan A - D yang dipilih paling ekonomis yaitu pada Pekerjaan C karena memerlukan biaya sebesar Rp. 71.394.879.243 lebih murah dan ekonomis.

Tabel 11. Simulasikan Biaya

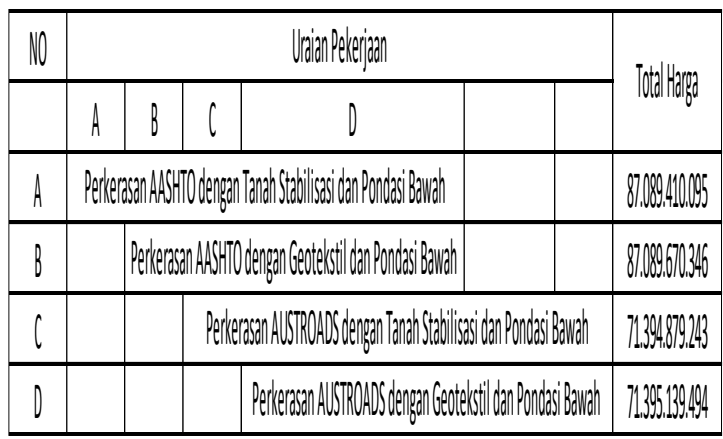

PERBANDINGAN METODE AASHTO 1993 DAN METODE AUSTROADS 2012
Terdapat parameter masukan yang berbeda antara kedua metode AASHTO 1993 dengan Austroads 2012 dalam menghitung perkerasan 5.50 akan disajikan lamgkah perhitungan perkerasan metode AASHTO 1993 dan Austroads 2012. Dapat dilihat pada tabel 11 sebagai berikut:

Tabel 12. perbandingan parameter metode AASHTO 1993 dan Austroads 2012

\begin{tabular}{|c|c|}
\hline Metode AASHTO 1993 & Metode Austroads 2012 \\
\hline 1. Menentukan umur rencana & 1. Menentukan umur rencana \\
\hline $\begin{array}{l}\text { 2. Menentukan nilai falator distribusi } \\
\text { arah dan lajur }\end{array}$ & 2. Lalu-lintas harian rata-rata \\
\hline 3. Lalu-lintas harian rata-rata & 3. Pertumbuhan lalu lintas per tahun \\
\hline 4. Perhitungan ESAL & 4. Bahan pondasi bawah \\
\hline 5. Realibility (R) & 5. Konfigurasi beban sumbu \\
\hline 6. Standar deviasi normal $\left(Z_{t}\right)$ & 6. Analisis jumlah kendaraan \\
\hline 7. Standar deviasi keseluruhan $\left(\mathrm{S}_{0}\right)$ & 7. Analisa sumbu kendaraan \\
\hline 8. Kemampuan pelayanan akhir (p) & 8. CBR $(\%)$ efehtif \\
\hline 9. Kemampuan pelayanan awal $\left(p_{0}\right)$ & 9. Faktor pertumbuhan lalu lintas $(\mathrm{R})$ \\
\hline 10. Kehilangan kemampulayanan & 10 Jumlah sumbu kendaraan niaga \\
\hline$(\triangle \mathrm{PSI})$ & 'selama umur rencana \\
\hline 11. Modulus reaksi tanah dasar (K) & 11 Proporsi beban kendaraan \\
\hline 12. Modulus elastisitas beton ( $E_{C}$ ) & 12 Proporsi sumbu kendaraan \\
\hline 13. Kuat lentur beton (Sc') & 12 Faktor Keamanan Beban (Fkb) \\
\hline 14. Koefisien drainase $(\mathrm{Cd})$ & 14 Kuat tarik lentur beton \\
\hline 15. Koefisien transfer beban (I) & 15 Tebal lapis pondasi \\
\hline \multirow[t]{6}{*}{ 16. Perhitumgan tebal pelat beton } & $\begin{array}{l}\text { 16 Perhitungan tebal pelat beton } \\
\text { (ditaksir terlebih dahulu) }\end{array}$ \\
\hline & 17 Menentukan tegangan ekivalen \\
\hline & 18 Faktor rasio tegangan \\
\hline & 19 Faktor erosi \\
\hline & 20 Analiga fatik \\
\hline & 21 Analisa erosi \\
\hline
\end{tabular}

Perbedaan hasil perhitungan dari kedua metode dikarenakan perbedaan parameter input data dari kedua metode tersebut yaitu:

\section{a. Pelat beton}

Metode Austroad 2012: pelat beton untuk perkerasan kaku ditentukan dari mutu pelat beton dengan ruji ataupun tanpa ruji, tebal pelat beton, kuat tekan beton dan kuat tarik lentur beton.

Metode AASHTO 1993: ditentukan koefisien transfer beban, jenis sambungan konstruksi menggunakan ruji atau tidak, dan kuat tekan beton.

b. Lalu lintas rencana

Metode Austroad 2012: lalu lintas dianalisis berdasarkan hasil perhitungan volume lalu lintas dan jumlah sumbu kendaraan niaga sesuai dengan konfigurasi sumbu dan 
memperhitungkan beban roda kendaraan niaga pada lajur rencana selama umur rencana.

Metode AASHTO 1993 : beban gandar kendaraan dikonversikan ke nilai ekivalen beban gandar tunggal sebesar $18 \mathrm{Kip}(80 \mathrm{KN}$ atau 8,16 Ton).

\section{c. Penentuan beban rencana}

Metode Austroad 2012: untuk menentukan besarnya beban rencana dengan cara jumlah total sumbu kendaraan niaga selama umur rencana dikalikan dengan faktor keamanan beban (FKB).

Metode AASHTO 1993: parameter seperti faktor distribusi arah (DD), faktor distribusi lajur (DL) dan vehicle damage factor dimasukkan untuk perhitungan lalu lintas rencana jumlah komulatif ekivalen sebesar 18 kip atau $80 \mathrm{KN}$ atau 8,16 Ton.

d. Tanah dasar

Metode Austroad 2012: dinyatakan dengan nilai CBR tanah dasar dan dikorelasikan dengan CBR efektif.

Metode AASHTO 1993: dinyatakan dengan modulus resilien (Mr) berdasarkan CBR dan memperhitungkan koefisien drainase $(\mathrm{Cd})$ dimana koefisien drainase tidak diperhitungkan didalam Austroad 2012.

Berdasarkan hasil analisis yang telah dilakukan, maka kesimpulan sementara adalah sebagai berikut:

1. Berdasarkan hasil analisis, perkerasan kaku pada ruas Jalan Tol Sentul Selatan Kedunghalang seksi I apabila menggunakan metode AASHTO 1993 didapatkan tebal Lean Concrete $10 \mathrm{~cm}$ dan tebal beton lapis permukaan $27 \mathrm{~cm}$, dan apabila menggunakan metode Austroads 2012 didapatkan tebal Lean Concrete $10 \mathrm{~cm}$ dan tebal beton lapis permukaan $21 \mathrm{~cm}$.

2 .

3. Berdasarkan hasil perhitungan analisis biaya didapatkan pada Pekerjaan A (Perkerasan AASHTO, Tanah Stabilisasi, dan Pondasi Bawah) memerlukan biaya sebesar Rp.87,089,410,095, apabila menggunakan Pekerjaan B (Perkerasan AASHTO, Geotekstil, dan Pondasi Bawah) memerlukan biaya sebesar Rp. $87,089,670,346$ apabila menggunakan
Pekerjaan C (Perkerasan AUSTROAD, Tanah Stabilisasi, dan Pondasi Bawah) memerlukan biaya sebesar Rp.71,394,879,243, dan apabila menggunakan Pekerjaan D (Perkerasan AUSTROADS, Geotekstil, dan Pondasi Bawah) memerlukan biaya sebesar Rp. $71,395,139,494$. Sehingga pada Pekerjaan C memerlukan biaya sebesar Rp.71,394,879,243 lebih murah atau lebih ekonomis.

\section{SIMPULAN}

Berdasarkan hasil analisis yang dilakukan, maka penulis dapat menarik kesimpulan sebagai berikut:

1. Perkerasan kaku pada ruas jalan tol Sentul Selatan - Kedunghalang seksi I, apabila menggunakan metode AASHTO 1993 didapatkan tebal Lean Concrete $10 \mathrm{~cm}$ dan tebal beton lapis permukaan $27 \mathrm{~cm}$, dan apabila menggunakan metode Austroads 2012 didapatkan tebal Lean Concrete $10 \mathrm{~cm}$ dan tebal beton lapis permukaan $21 \mathrm{~cm}$

2. Biaya Pekerjaan A (Perkerasan AASHTO, Tanah Stabilisasi, dan Pondasi Bawah) memerlukan biaya sebesar Rp.87,089,410,095, apabila menggunakan Pekerjaan B (Perkerasan AASHTO, Geotekstil, dan Pondasi Bawah) memerlukan biaya sebesar Rp.87,089,670,346, apabila menggunakan Pekerjaan C (Perkerasan AUSTROAD, Tanah Stabilisasi, dan Pondasi Bawah) memerlukan biaya sebesar Rp.71,394,879,243, dan apabila menggunakan Pekerjaan D (Perkerasan AUSTROADS, Geotekstil, dan Pondasi Bawah) memerlukan biaya sebesar Rp. 71,395,139,494. Sehingga pada Pekerjaan $\mathrm{C}$ memerlukan biaya sebesar Rp.71,394,879,243 lebih murah atau lebih ekonomis. 


\section{DAFTAR PUSTAKA}

Apriyatno, T. 2015. Uji Komparasi Perancangan Tebal Perkerasan Lentur dan kaku Metode AASHTO 1993. Jurnal Teknik Sipil dan Perencanaan, 17(1), 51 - 62. (1)

Ardiyatmo, H. C. 2007. Perancangan Perkerasan Jalan dan Penyelidikan Tanah. Yogyakarta: Gajah Mada University Press (6)

Bethary, Rindu Twidi; et , al. 2015. Analisis Kerusakan dan Perencananaan Tebal Perkerasan Jalan Kaku dengan Metode Bina Marga 2003. Jurnal Fondasi, Volume 4 Nomor 2, 39 - 40. (2)
Cahyono, w., \& Rifa'i, A. 2018. stabilisasi tanah dasar dengan bahan adiktif akibat beban siklik jalan rel kereta cepat jakarta - bandung . media teknik sipil, 70-79. (3)

Hardiyatmo. 2011. Perancangan Perkerasan Jalan dan Penyelidikan Tanah. Yogyakarta: Gadjah Mada University Press (4)

Hendarsin, S. 2000. Perencanaan Teknik Jalan Raya. Bandung: Politeknik Negeri Bandung. (5) 